\title{
United Nations Development Programme
}

\section{\& Climate Change Adaptation}

\author{
- A Quarterly Update of Activities -
}

This bulletin provides the latest information on UNDP's support to countries to effect policy and institutional change for Climate Change Adaptation at the national, sub-national and community-level. It includes updates on a range of topics including the status of ongoing projects, new project approvals, performance indicators, project impacts and results, and noteworthy announcements.

For contributions to future editions of the newsletter, please write to adaptation@undp.org

Welcome to the third issue of UNDP's Bulletin on Climate Change Adaptation. In this edition, we highlight: (1) UNDP's support to Least Developed Countries; (2) a UNDP signature programme of assistance to Africa called the Africa Adaptation Programme (AAP) financed by the Government of Japan; and (3) Country updates on preparation and implementation of adaptation initiatives.

Supporting Least Developed Countries (LDCs) to Access Adaptation Finance

UNDP currently supports more than $70 \%$ of all LDCs to access financing from multiple sources including the adaptation funds managed by the Global Environment Facility (GEF) as well as resources from the Government of Japan (see next page). In a number of cases, countries are pioneering various ways in which to adapt to climate change with the support of UNDP's network of professionals at the country, regional and global levels.

\section{FAST FACTS on UNDP's portfolio in Least Developed Countries}

Total number of projects UNDP is supporting with accessing resources from the Least Developed Country Fund (LDCF), as of end-2009

Total number of LDCF projects under implementation, as of Mar-2010

Total number of additional LDCF projects expected to begin implementation during Q2 2010

Total number of additional LDCF projects expected to begin implementation during Q3 \& Q4 2010

Total number of additional countries UNDP has been asked to support with accessing LDCF resources (since 5 Jan 2010)

\section{Mainstreaming Adaptation: Going Beyond Environment}

As climate change risk management and poverty reduction are inextricably linked, UNDP's support to countries on adaptation builds on and goes beyond working with Ministries of Environment. UNDP is supporting key sector Ministries in Agriculture, Economic Affairs, Energy, Finance, Fisheries, Forests, Geology, Health, Mineral Resources, National Planning, Public Works, Science \& Technology, Transport, Tourism, Urban Development, Water, among others, to integrate consideration of climate change risks and opportunities into the overall governance of their respective sectors. UNDP's technical assistance extends to supporting policy makers and technical officials at the Provincial-, District-, Municipal-Level Authorities as well as Non-Governmental Organizations and Community-based Organizations to establish organizational frame-

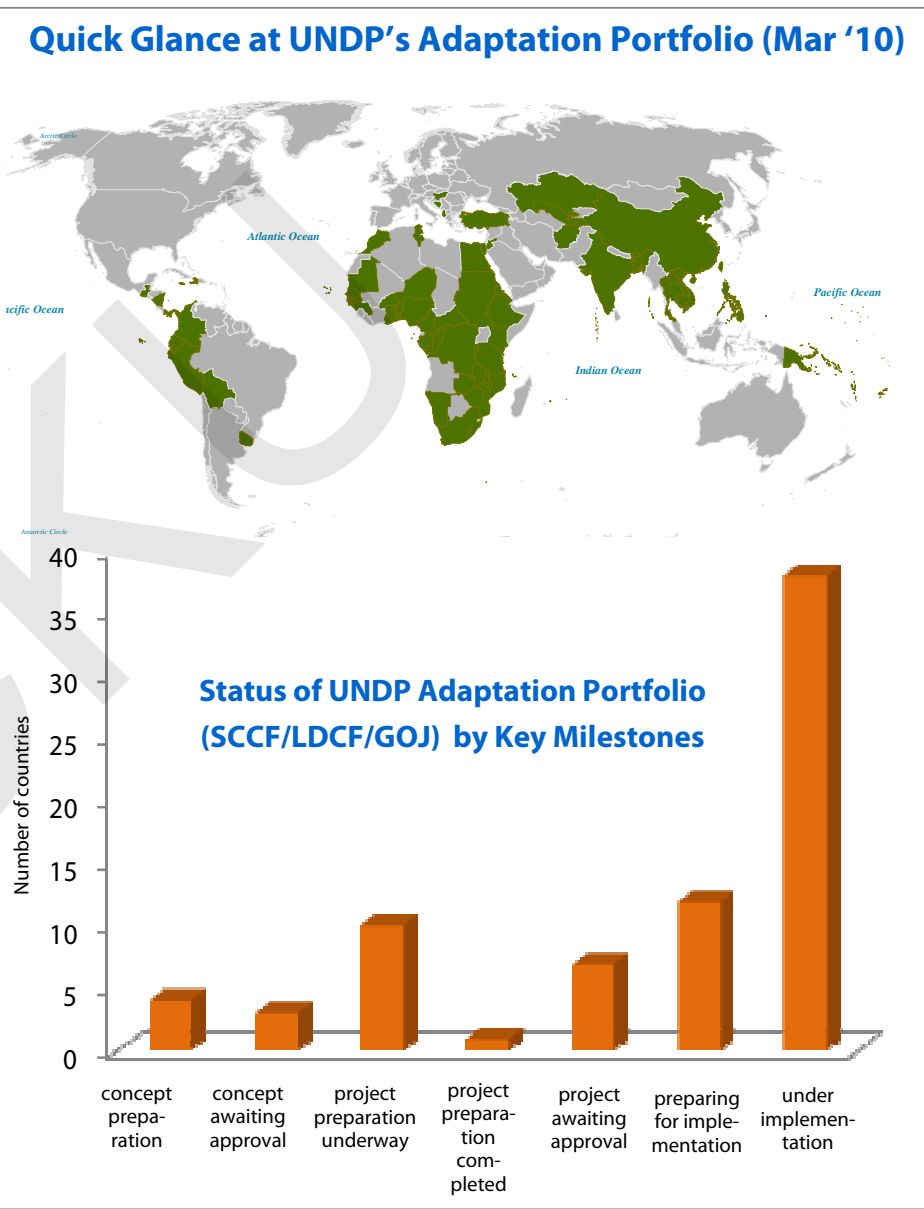

works as well as strengthening relevant technical capacities and institutions, for supporting and facilitating climate change risk management.

Leveraging Comparative Strengths of Other Multilateral Agencies

UNDP partners with a number of multilateral agencies to support countries to adapt at the national, sub-national and community level. This includes partnerships with Asian Development Bank (Vietnam), Food and Agriculture Organization (Mali), Red Cross Society (Thailand), Southern Pacific Regional Environmental Programme (Regional-Pacific), United Nations Environment Programme (Comoros, Rwanda), United Nations Volunteers (in 10 countries), World Bank Group (Kenya), and World Health Organization (in 7 countries).

For further information, please visit: www.undp.org/climatechange

NOTES: GEF- Global Environment Facility; GOJ-Government of Japan; SPA- Strategic Priority on Adaptation (GEF Trust Fund); LDCF- Least Developed Countries Fund (UNFCCC Fund); SCCF- Special Climate Change Fund (UNFCCC Fund). 


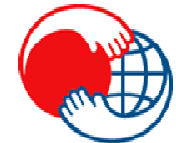

JAPAN

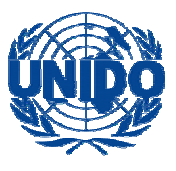

(iv)

unicef (3)

\section{Support to National Initiatives}

An Inter-Regional Technical Support Component (IRTSC) based in Dakar serves as the engine room for the coordination of technical assistance to country initiatives.

In direct relationship to the overall programme purpose and outcomes of each national initiative, the IRTSC will:

\section{AFRICA ADAPTATION PROGRAMME}

In December 2008, UNDP, in partnership with UNIDO, UNICEF and WFP, launched a US\$92 million programme, "Supporting Integrated and Comprehensive Approaches to Climate Change Adaptation in Africa" , funded by the Government of Japan.

The Africa Adaptation Programme (AAP) was established under the JapanUNDP Joint Framework for Building Partnership to Address Climate Change in Africa, which was established at the Fourth Tokyo International Conference on African Development, organized in Yokohama, Japan in May 2008.

The AAP provides financial resources to 20 countries across the African continent to incorporate climate change risks and opportunities into national development processes. The national projects have been designed to further develop country capacities to successfully identify, design and implement holistic adaptation and disaster risk reduction programmes that are aligned with national development priorities. In this regard, AAP is a strategic initiative, aimed at creating an environment for more informed and capable adaptation decisions and practice in each country.

Key outcomes of the national initiatives include: (a) strengthening long-term planning to prepare countries to manage both existing and future risks associated with climate change, (b) building efficient leadership and institutional frameworks for enhanced coordination and cohesion of programmes, (c) supporting the piloting of adaptation initiatives in the field, (d) identifying a range of financing options for sustained adaptation, and (e) building knowledge management systems and promoting information sharing.

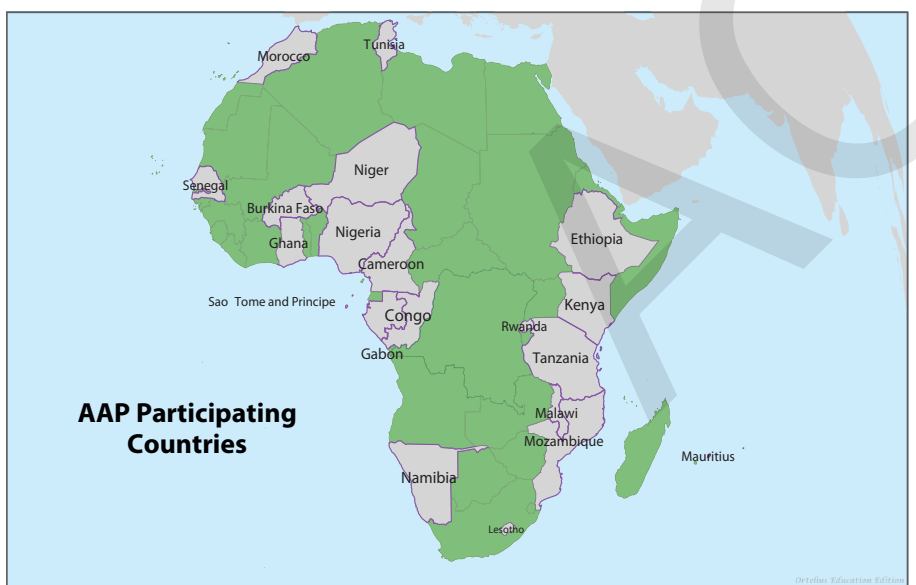

1 Facilitate country access to best available data and information on climate variability and impacts.

2 Support institutional and leadership development through structured and specific interventions that are responsive to the unique circumstances and needs of each country

3 Make available to countries best practices, experiences and technologies for facilitating the implementation of climate resilient policies in priority sectors.

4 Provide countries with information on innovative financing options.

5 Create a region wide knowledge and learning mechanism to raise awareness engage stakeholders, inform decision makers and promote exchange and cooperation between countries.

The AAP builds on a range of related disaster risk reduction and development opportunities and, through the broader UNDP networks, brings to bear the expertise of WFP, UNICEF, UNIDO and other UN Agencies to implement a number of programmed activities in selected countries. As a strategic framework, the AAP is expected to lay the foundations for follow-up investments by the World Bank and other multilateral financial institutions in addition to enhancing the value adding of existing adaptation programmes such as those supported by EC, GEF (LDCF, SCCF, SPA) and Bilateral donors (see below).

For more information, visit the AAP project website: http://www.undpadaptation.org/africaprogramme or contact Mr. Ian Rector, AAP Programme Manager, lanR@unops.org and Ms. Mihoko Kumamoto, Technical Advisor, mihoko.kumamoto@undp.org

\begin{tabular}{|lc|ll|}
\hline \multicolumn{4}{c}{ Status of AAP National } \\
\hline Burkina Faso & completed Jan-10 & Morocco & confirmed Apr-10 \\
\hline Cameroon & confirmed Apr-10 & Mozambique & completed Mar-10 \\
\hline Congo & date to be confirmed & Namibia & completed Feb-10 \\
\hline Ethiopia & confirmed Apr-10 & Niger & confirmed Apr-10 \\
\hline Gabon & completed Mar-10 & Nigeria & date to be confirmed \\
\hline Ghana & completed Mar-10 & Rwanda & confirmed Apr-10 \\
\hline Kenya & completed Mar-10 & Sao Tome \& P & completed Mar-10 \\
\hline Lesotho & completed Mar-10 & Senegal & confirmed Apr-10 \\
\hline Malawi & confirmed Apr-10 & Tanzania & confirmed Apr-10 \\
\hline Mauritius & confirmed Apr-10 & Tunisia & completed Feb-10 \\
\hline
\end{tabular}

\section{Overview of Namibia's AAP project}

Namibia faces serious climate change risks such as a hotter climate, more arid conditions and both more frequent and extreme weather events. The country has already placed a certain level of institutional and human capacities to cope with climate change risks. Through stakeholder consultations Namibia identified further needs to strengthen policy and institutional frameworks for climate change risk management. Additionally, the country identified strong needs to develop adaptive capacities of rural people as they are at direct risk to climate change and least equipped to cope with risks due to linguistic/cultural diversity, vast distances and legacy of historical challenges.

A diversity of adaptation-related work is already ongoing in Namibia. For example, Namibia implements a UNDP/GEF financed pilot project in Omusati region, promoting the use of climate resilient crops and livestock in the north. In addition, Namibia is implementing a series of Community-Based Adaptation (CBA) projects with UNDP/GEF support in the northern region. Furthermore, Namibia benefits from UNDP's support to establish climate change-related Investment and Financial Flows, and is currently preparing its Second National Communication to the UNFCCC. UNDP Namibia is working with the Government to strengthen the country's responses to disaster and has been guiding the development of a new Disaster Risk Management Policy.

In the context of the above initiatives, Namibia is expected to work towards the achievement of the following outcomes with financing from the UNDP/GOJ: 1) Strengthening adaptation long-term planning capacity; 2) Developing institutional and individual capacities with a focus on the youth; 3) Implementing policies and measures in priority sectors such as floods/settlements and sanitation/health; 4) Developing innovative financing mechanisms; 5 ) Implementing knowledge management activities. 


\section{Community-Based Adaptation Conference}

At the 4th International Conference on Community-Based Adaptation in Dar es Salaam (21-27 February 2010) UNDP highlighted its support to community based adaptation in over 33 countries, financed by the LDCF, SCCF and SPA. Grants of up to US\$50,000 are currently being provided by the UNDPimplemented GEF/Small Grants Programme to community-based projects focusing on climate risk management practices. Projects include: climateresistant watershed management in Bolivia, reducing climate-driven coastal hazards such as erosion resulting from increasing storm intensity in Samoa, winter irrigation to replace water from declining snowfalls in Kazakhstan, improving the efficiency of water use in Namibia, and managing flood risks in the Mekong Delta. Additional information on the conference can be found in the UNDP Press Release: http://content.undp.org/go/newsroom/publications/ environment-energy/www-ee-library/climate-change/UNDP-calls-for-partners-to -scale-up-climate-change-adaptation.en

For details on the CBA project, please visit: http://www.undp-adaptation.org/ project/cba

For more information on CBA, contact Mr. Delfin Ganapin, Global Manager, Small Grants Programme, delfin.ganapin@undp.org

\section{MDG-F - Turkey}

Further to last issue's feature on the environment and climate change window of the Millennium Development Goals Achievement Fund (MDG-F), we are pleased to highlight the joint programme Enhancing the Capacity of Turkey to Adapt to Climate Change - www.climate.mdgf-tr.org. The first goal of the programme is to contribute to the reduction of the risks of climate change in the process of achieving MDGs. The second goal aims to determine priorities in climate risk management and take adaptation precautions for the development of the capacity for adjustment. Reinforcing the first two goals, the third goal encourages the implementation of sustainable development policies in accordance with climate risks and adaptation requirements. While developing the Seyhan River Basin's capacity to adapt to climate change, the goals will create new social and institutional perspectives to the area through providing support to innovative adaptation activities in the area.

\section{Additional LDCs to be supported by UNDP}

In response to requests from the Governments of Chad, Ethiopia, Lesotho, Mozambique, and Togo, UNDP has initiated support to develop NAPA followup projects, funded by the LDCF.

\section{Adaptation Learning Mechanism (ALM)}

The ALM (http://www.adaptationlearning.net) is a knowledge-sharing platform maintained by UNDP in close partnership with the GEF, UNFCCC, the World Bank and specialized UN agencies (e.g., FAO, UNEP, etc). The ALM is funded by the GEF Trust Fund until December 2010.

The ALM provides access to vetted information on experiences and lessons from programs and projects at the national or community-level that promote/facilitate adaptation to climate change. The facility has built-up an information portal providing more than 850 tailored adaptation resources and features over 170 Adaptation Country Profiles. Each profile contains an overview of information relevant to a country to inform the design of adaptation initiatives adaptation, including summaries on National Communications (NCs), National Adaptation Programmes of Action (NAPAs), climate change scenarios, impact assessments and relevant low-carbon/adaptation strategies.

The platform has approximately $80-250$ visitors daily, with over 700 registered users from over 165 countries (see figure on right). Seventy-nine percent of users are from Non-Annex I and GEF-eligible countries.

The ALM was featured during COP-15 as a jointly facilitated UN initiative that contributes to the implementation of the UNFCCC's Nairobi Work Programme.

http://www.unsceb.org/ceb/ priorities/climate-change/cop15

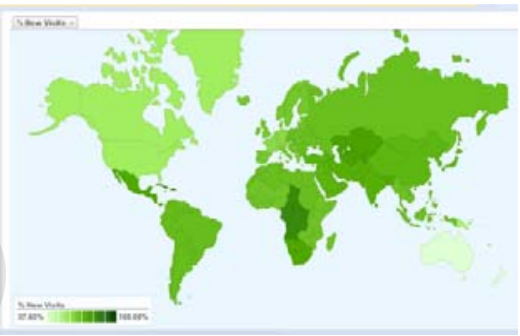

Please join ALM on Twitter: http://twitter.com/almplatform and Facebook http://www.facebook.com/profile.php?id=100000473266831

For more further information on ALM, please contact Ms. Julia Wolf, Project Manager, julia.wolf@undp.org

For LDCF/SCCF/SPA projects, contact Mr. Pradeep Kurukulasuriya, Senior Technical Advisor, pradeep.kurukulasuriya@undp.org

\section{National Adaptation Programme of Action (NAPA)}

UNDP supported 31 countries with development of a NAPA. Of these, 29 have completed their NAPAs and are currently designing or implementing NAPA follow-up projects, many with UNDP support Below is a status update from the two countries that are due to complete their NAPA in 2010.

Nepal (from the NAPA Bulletin January-February 2010): A national workshop took place on 7 February 2010 to review a recently completed report which synthesizes the outputs of the six government-led NAPA Thematic Working Groups (TWG) on agriculture and food security; climate-induced disasters; forests \& biodiversity; water resources and energy; public health; and urban settlements \& infrastructure. The report describes the country context and climate change implications for Nepal, the approach to NAPA development, the progress and achievements during the first phase of work during 2009, and the forward plan towards finalization and follow-up of the NAPA by August 2010. The TWGs support the NAPA preparation process by undertaking information gathering and analysis, vulnerability assessments, facilitating engagement with various stakeholders.

On 18 January 2010, the Ministry of Environment convened a brainstorming workshop on establishing a national climate change knowledge management platform under the NAPA project. The Honorable Minister Thakur Prasad Sharma, Ministry of Environment delivered the inaugural address. He highlighted the importance of a good knowledge management platform that will bring together government, media, civil society, international organizations, and development partners, to supply information and knowledge requirements for adaptation planning, policymaking and formulating adaptation programmes. For more information, please visit: http://www.napanepal.gov.np

Timor-Leste (from UNDP's Poverty Reduction and Environment Unit in Dili): Since December 2009 there has been rapid progress in the Timor -Leste NAPA process. A widespread renewed interest and enthusiasm for the process has coincided with the appointment of both National and International Consultants to work alongside the existing team. Government representatives of all levels, National and International NGOs, academic institutions, bilateral development partners and UN agencies have all actively engaged in recent activities. The widening of stakeholder involvement is an encouraging demonstration of the increasing interest in climate change issues. In particular, this was evident at a joint Sector Working Group meeting held in February 2010 and at a post-Copenhagen meeting in the same month at which both Government at Ministerial Level and UN at acting Special Representative of the Secretary General (SRSG) level were represented. At this meeting, the Minister of Economy and Development stressed that the implementation of NAPA is a 'must' and unveiled elements of what he described as a coordinated, multi-sectoral Climate Change strategy incorporating an adaptation plan for Timor-Leste or a road map for the next decade.

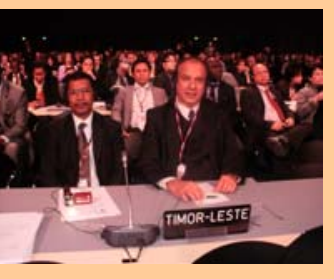

This renewed energy has been paralleled on the practical side with considerable progress made towards synthesizing current information, performing a comprehensive stakeholders' analysis and finalizing the methodology for the Vulnerability and Adaptation Capacity Assessment. Under the leadership of the National Director for International Environmental Affairs, NAPA's International Consultant has helped to guide the development of a four-step methodology which takes into account the specific circumstances of Timor-Leste, draws efficiently on existing resources and further fosters close collaboration amongst all stakeholders. In March 2010, the first step will facilitate the exchange of learning and experiences with conducting participatory physical and social vulnerability assessments of various types within the country. This will provide government departments and NGOs with the opportunity to together analyze what they have done in the past and to identify how such experience can be applied for the benefit of the current process.

In this way, the NAPA in Timor-Leste is developing into a truly country-owned process in which a wide variety of stakeholders are actively engaged. 
STATUS OF UNDP SUPPORTED ADAPTATION INITIATIVES

\begin{tabular}{|c|c|c|c|c|c|c|c|}
\hline REGION & COUNTRY & SOURCE OF FUNDS & GRANT (US\$) & REGION & COUNTRY & SOURCE OF FUNDS & GRANT (US\$) \\
\hline \multicolumn{4}{|c|}{ CONCEPT PREPARATION } & \multicolumn{4}{|c|}{ PROJECTS UNDER IMPLEMENTATION } \\
\hline \multirow{4}{*}{ Africa } & Central African Republic & LDCF & $5,000,000$ & \multirow{18}{*}{ Africa } & Burkina Faso & GOJ & $2,901,000$ \\
\hline & Lesotho & LDCF & $5,000, .00$ & & Burkina Faso & LDCF & $2,900,000$ \\
\hline & Mozambique & LDCF & $5,000,000$ & & Cape Verde & LDCF & $3,000,000$ \\
\hline & Togo & LDCF & $5,000,000$ & & Eritrea & LDCF & $3,320,000$ \\
\hline \multicolumn{4}{|c|}{ CONCEPT AWAITING APPROVAL } & & Ethiopia & SCCF & 995,000 \\
\hline \multirow{3}{*}{ Africa } & Ethiopia & LDCF & $5,310,000$ & & Ghana & GOJ & $2,710,000$ \\
\hline & Syaziland & SPA & (200000 & & Kenya & SCCF & $1,000,000$ \\
\hline & swazilana & SPA & 900,000 & & Mauritius & GOJ & $2,987,000$ \\
\hline Central Asia & Armenia & SPA & $1,720,000$ & & Mozambique & GOJ & $2,990,000$ \\
\hline & PROJECT PREPAR & ON UNDERWAY & & & Mozambique & SCCF & 960,000 \\
\hline \multirow{4}{*}{ Africa } & Comoros & LDCF & $2,500,000$ & & Namibia & GOJ & $2,980,000$ \\
\hline & Ghana & SCCF & $1,800,000$ & & Namibia & SPA & 960,000 \\
\hline & Guinea Bissau & LDCF & $4,100,000$ & & Niger & LDCF & $3,500,000$ \\
\hline & South Africa & SCCF & $3,530,000$ & & Sao Tome \& Principe & GOJ & $2,750,000$ \\
\hline \multirow{3}{*}{ Asia } & Lao & LDCF & $4,500,000$ & & Tanzania & SCCF & $1,000,000$ \\
\hline & Thailand & SCCF & 870,000 & & Zambia & LDCF & $3,795,000$ \\
\hline & Vietnam & SCCF & $1,220,000$ & & Zimbabwe & SCCF & 983,000 \\
\hline $\begin{array}{l}\text { Latin America } \\
\text { and Caribbean }\end{array}$ & Haiti & LDCF & $3,600,000$ & & $\begin{array}{l}\text { Cape Verde, Gambia, Guinea } \\
\text { Bissau, Mauritania, Senegal }\end{array}$ & SPA & $3,300,000$ \\
\hline Pacific & Samoa & LDCF & $2,400,000$ & \multirow{3}{*}{ Arab States } & Egypt & SCCF & $4,000,000$ \\
\hline \multicolumn{4}{|c|}{ PROJECT PREPARATION COMPLETED } & & Sudan & LDCF & $3,300,000$ \\
\hline \multirow[t]{2}{*}{ Asia } & India & SCCF & $5,300,000$ & & Tunisia & GOJ & $2,975,000$ \\
\hline & \multicolumn{2}{|c|}{ PROJECTS AWAITING APPROVAL } & & \multirow{5}{*}{ Asia } & Bangladesh & LDCF & $3,300,000$ \\
\hline \multirow{6}{*}{ Africa } & Congo & GOJ & $2,975,000$ & & Bhutan & LDCF & $3,445,000$ \\
\hline & Liberia & LDCF & $3,000,000$ & & Cambodia & LDCF & $1,850,000$ \\
\hline & Malawi & GOJ & $3,882,000$ & & India & SPA & 200,000 \\
\hline & Nigeria & GOJ & $5,475,000$ & & Maldives & LDCF & $4,485,000$ \\
\hline & Rwanda & GOJ & $2,933,000$ & \multirow{5}{*}{$\begin{array}{l}\text { Europe and } \\
\text { Central Asia }\end{array}$} & Albania & SPA & 975,000 \\
\hline & Senegal & GOJ & $3,000,000$ & & & & \\
\hline \multicolumn{4}{|c|}{ PROJECTS RECENTLY APPROVED } & & Armenia & SPA & 900,000 \\
\hline \multirow{11}{*}{ Africa } & Benin & LDCF & $3,140,000$ & & Hungary & SPA & 985,000 \\
\hline & Cameroon & GOJ & $3,000,000$ & & Tajikistan & SPA & 950,000 \\
\hline & Dem. Rep. of Congo & LDCF & $3,000,000$ & \multirow{2}{*}{$\begin{array}{l}\text { Latin America } \\
\text { and Caribbean }\end{array}$} & Ecuador & SCCF & $3,000,000$ \\
\hline & Ethiopia & GOJ & $6,483,000$ & & Uruguay & SPA & 975,000 \\
\hline & Gabon & GOJ & $2,465,000$ & \multirow{4}{*}{ Pacific } & Samoa & LDCF & $2,000,000$ \\
\hline & $\begin{array}{l}\text { Guinea } \\
\text { Kenya }\end{array}$ & GOJ & $\begin{array}{r}2,9 / 0,000 \\
5,470000\end{array}$ & & Tuvalu & LDCF & $3,300,000$ \\
\hline & Lesotho & GOJ & $2,975,000$ & & Pacific Adaptation Project (13 & SCCF & 13.500000 \\
\hline & Mali & LDCF & $2,340,000$ & & PICs) & ser & $13,500,000$ \\
\hline & Niger & GOJ & $3,000,000$ & \multirow{5}{*}{ Global } & \multirow{2}{*}{$\begin{array}{l}\text { Adaptation Learning Mecha- } \\
\text { nism }\end{array}$} & \multirow{2}{*}{ SPA } & 724,000 \\
\hline & Rwanda & LDCF & $1,991,000$ & & & & \\
\hline & Tanzania & GOJ & $2,972,000$ & & Bangladesh, Bolivia, Guate- & & \\
\hline \multirow{2}{*}{$\begin{array}{c}\text { Arab States } \\
\text { Global }\end{array}$} & Morocco & GOJ & $2,975,000$ & & $\begin{array}{l}\text { mala, Jamaica, Kazakhstan, } \\
\text { Morocco, Namibia, Niger, }\end{array}$ & SPA & $4,525,000$ \\
\hline & Global Health & SCCF & $4,500,000$ & & Samoa, and Vietnam & & \\
\hline
\end{tabular}

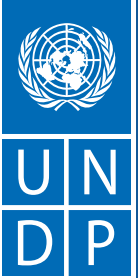

For additional information, please contact:

Veerle Vandeweerd

Director

Environment \& Energy Group

veerle.vandeweerd@undp.org

Tel: +1 2129065020
Yannick Glemarec

Executive Coordinator, UNDP/GEF and

Director, Environmental Finance

yannick.glemarec@undp.org

Tel: +1 2129065143 